University of Nebraska - Lincoln

DigitalCommons@University of Nebraska - Lincoln

March 1992

\title{
OBSERVATIONS OF A GAS EXPLODING DEVICE FOR CONTROLLING BURROWING RODENTS
}

Monty Sullins

Montana Department of Agriculture

Daniel Sullivan

Montana Department of Agriculture

Follow this and additional works at: https://digitalcommons.unl.edu/vpc15

Part of the Environmental Health and Protection Commons

Sullins, Monty and Sullivan, Daniel , "OBSERVATIONS OF A GAS EXPLODING DEVICE FOR CONTROLLING BURROWING RODENTS" (1992). Proceedings of the Fifteenth Vertebrate Pest Conference 1992. 76. https://digitalcommons.unl.edu/vpc15/76

This Article is brought to you for free and open access by the Vertebrate Pest Conference Proceedings collection at DigitalCommons@University of Nebraska - Lincoln. It has been accepted for inclusion in Proceedings of the Fifteenth Vertebrate Pest Conference 1992 by an authorized administrator of DigitalCommons@University of Nebraska Lincoln. 


\section{OBSERVATIONS OF A GAS EXPLODING DEVICE FOR CONTROLLING BURROWING RODENTS}

MONTY SULLINS and DANIEL SULLIVAN, Montana Department of Agriculture, Capitol Station, Helena, Montana 59620

ABSTRACT: Field trials were conducted to test the effectiveness of a gas exploding device called "Rodentorch" in reducing pest populations of ground squirrels and prairie dogs. Ignition of a propane/oxygen mixture injected for 30 seconds into burrows reduced prairie dog activity $13.0 \%$. Doubling the injection time in prairie dog burrows to 60 seconds resulted in a $63.3 \%$ reduction. Reduction in ground squirrel activity was $40.6 \%$ after a 45 second injection time. Comparative trials on ground squirrels using EPA registered gas cartridge and aluminum phosphide fumigants resulted in $90.8 \%$ and $83.7 \%$ reduction in activity, respectively.

Proc. 15th Vertebrate Pest Conf. (J. E. Borrecco \& R. E. Marsh, Editors) Published at University of Calif., Davis. 1992

\section{INTRODUCTION}

Recent cancellations by the U.S. Environmental Protection Agency (EPA) of rodenticide registrations, such as Compound 1080 and strychnine, have greatly reduced toxicants available to control damage caused by field rodents. The high cost of research to register new rodenticides or to maintain existing registrations cause doubt that field rodenticides will remain available. Therefore, methods of rodent control other than chemical toxicants need to be researched.

One such method which uses a concussion device sold under the brand name "Rodentorch" has been developed for control of burrowing rodents. Initial development occurred in Nevada for use on pocket gophers (Thomomys spp). This is a portable system that mixes propane and oxygen gases which are injected into rodent burrow systems and ignited. The concussion caused by the explosion reportedly kills the rodents within the burrow system.

A distributorship for the device has been established in Montana but field data on its effectiveness are not available. Such data are needed before recommendations on its use can be made to landowners and rodent control personnel.

\section{OBJECTIVE}

The objectives of this study were to determine the effectiveness of the "Rodentorch" in reducing black-tailed prairie $\operatorname{dog}$ (Cynomys ludovicianus) and Richardson ground squirrel (Spermophilus richardsonii) populations and to record the cost and labor required for treatment.

\section{STUDY AREA}

Prairie Dog

A 20 acre prairie dog town, located on a private ranch in eastern Yellowstone County near Billings, Montana, was chosen for treatment in this study. The study site was located on a dryland sagebrush/grass pasture used for summer cattle grazing. Emergent vegetation was sparse to nonexistent within the prairie dog town. The prairie dog portion of this evaluation was conducted during the first 2 weeks of May, 1990.

\section{Ground Squirrel}

Four small ground squirrel colonies totaling about 7 acres were selected on agricultural land in Broadwater County east of Townsend, Montana. The test sites were grassland patches bordering cultivated cropland. This portion of the study was conducted in mid-May 1991.

\section{METHODS}

The gas mixture was applied by a commercially made concussion device called a "Rodentorch." This device is composed of a $5 \mathrm{ft}(1.5 \mathrm{~m})$ wand attached by two gas hoses and an electrical wire to oxygen and propane tanks and an electrical source. A valve that allows the gases to mix and flow through the wand and an electrical switch are located at one end of the wand. At the other end of the wand, enclosed in an open metal cylinder, is the outlet for the gases and an automotive spark plug (Figure 1).

Two people were involved in the actual application. One person drove a pickup containing the gas cylinders and the other person operated the device (Figure 2). Time and cost of applications were recorded.

\section{Prairie Dog}

The prairie dog town was divided into 3 plots. One plot served as a no treatment control. The burrows on the remaining 2 plots received the injected propane/oxygen mixture for 30 and 60 seconds, respectively.

Prior to treatment, all prairie dog burrow openings were covered with dry cow chips. Only those burrows reopened after 3 days were treated.

Percent reduction in prairie dog numbers was determined by counting active prairie dogs on each plot before and after treatment. Visual counts using binoculars were obtained on marked counting areas within each treatment and control plot. Three counts were made at five minute intervals on each plot for three consecutive days before and after treatment. The nine pretreatment and posttreatment visual counts were averaged to compute activity indices (AI) for each plot. Percent reduction in activity caused by the "Rodentorch" was computed as follows:

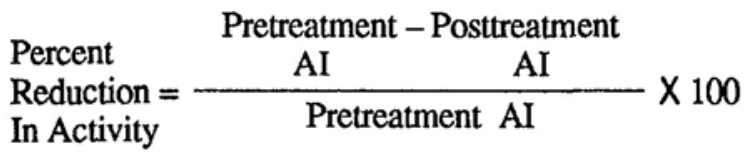

\section{Ground Squirrel}

One ground squirrel colony was selected for treatment with the device. The gas mixture was injected into each burrow treated for 45 seconds. Two other colonies were treated with EPA registered gas cartridge ${ }^{1}$ and aluminum phosphide ${ }^{2}$

\footnotetext{
${ }^{1}$ USDA, APHIS; Application Rate: 1 Cartridge/Burrow

${ }^{2}$ Research Products Co.; Application Rate: 2 tablets/burrow
} 


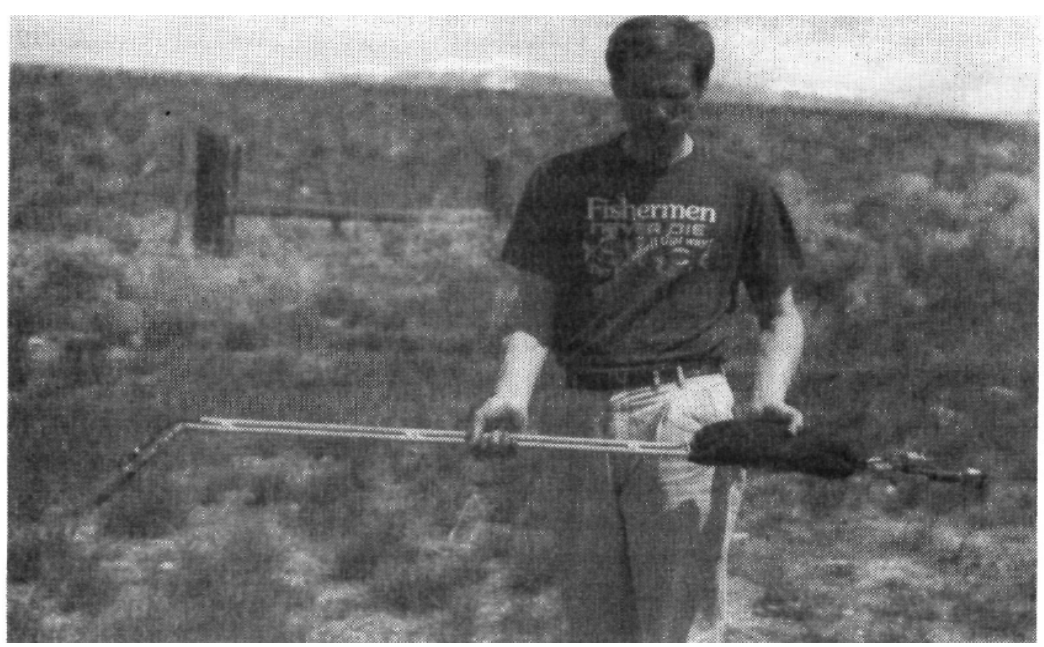

Figure 1. "Rodentorch" application wand. The value and electrical switch are on the viewer's right, the gas outlet and spark plug are on the left. The enlarged area to the right of center is a condenser. (D. Sullivan photo)

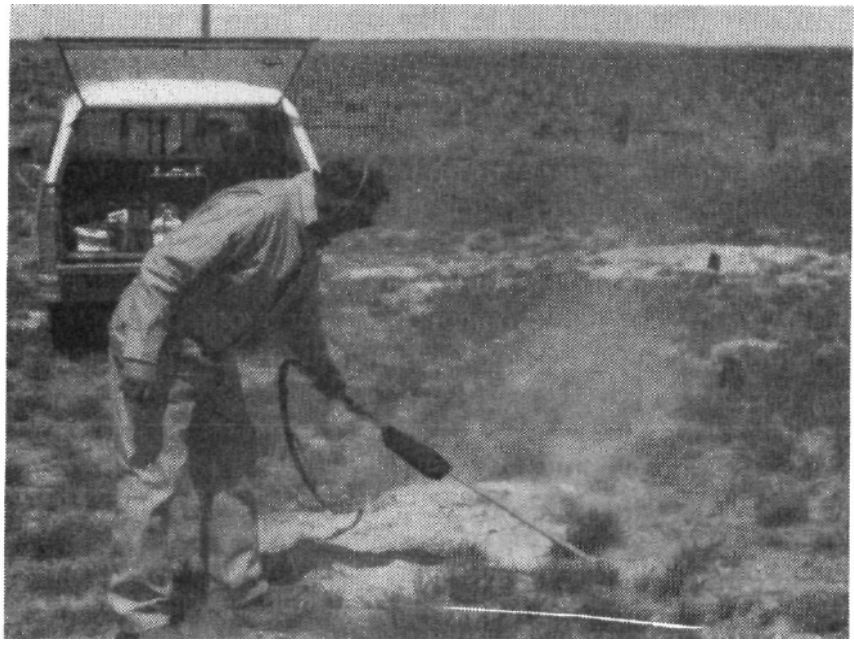

Figure 2. "Rodentorch" application. The application wand is attached to propane and oxygen tanks and an electrical source by hoses and wire located in the truck behind the applicator. (D. Sullivan photo)

burrow fumigants, respectively. The fourth colony was used as a control site and received no treatment.

Vegetation height on the ground squirrel plots prevented use of visual counts. Percent reduction in activity was determined by measuring reduction in active burrows. Prior to treatment all burrows on each study plot were closed with loose soil. All burrows opened within two days were considered active, marked with survey flags and treated. Two days after treatment the burrows that were marked as active were again closed. Burrows reopened within two days were considered active. Percent reduction in activity was calculated as follows:

\begin{tabular}{|c|c|c|}
\hline & $\begin{array}{c}\text { No. Active } \\
\text { Burrows } \\
\text { Pretreatment }\end{array}$ & $\begin{array}{c}\text { No. Active } \\
-\quad \text { Burrows } \\
\text { Posttreatment }\end{array}$ \\
\hline & $\begin{array}{l}0 . \mathrm{A} \\
\mathrm{Pr}\end{array}$ & $\begin{array}{l}\text { Burrows } \\
\text { tment }\end{array}$ \\
\hline
\end{tabular}

RESULTS

$\underline{\text { Prairie Dog }}$

Percent reduction in activity on the treated plots was $13.0 \%$ for the 30 -second injection and $63.3 \%$ for the 60 second injection (Table 1). No significant change in activity occurred on the control plot.

Pretreatment burrow closures required 1.77 and 1.85 man-hours for the 30 -second and 60 -second plots, respectively (Table 1$)$. The 30 -second plot ( 6.8 acres) required 2.5 man-hours to treat 51 burrows. A total of 145 burrows were treated on the 60 -second plot (9.3 acres) requiring 9.0 manhours of labor (Table 1). Total cost of the gases used on both treated plots was approximately $\$ 2.30$ for propane and $\$ 13.65$ for the oxygen.

\section{Ground Squirrel}

Percent reduction in activity on the "Rodentorch" plot was $40.6 \%$ (Table 2). This compares with $90.8 \%$ and $83.7 \%$ reduction in activity on the gas cartridge and aluminum phosphide plots, respectively. Treatment time was 2.80 man-hours/ 100 burrows for the "Rodentorch" application, 1.61 manhours/100 burrows for the aluminum phosphide application

Table 1. Efficacy, application labor and cost of the "Rodentorch" concussion device at two injection times on black-tailed prairie dogs.

\begin{tabular}{|c|c|c|c|c|c|c|}
\hline Plot & $\begin{array}{c}\text { Burrows } \\
\text { Closed }\end{array}$ & $\begin{array}{c}\text { Reopened } \\
\text { Burrows } \\
\text { Treated }\end{array}$ & $\begin{array}{c}\begin{array}{c}\text { Pretreatment } \\
\text { Burrow Closure }\end{array} \\
\text { Man-hrs/100 burrows }\end{array}$ & $\begin{array}{c}\text { Treatment } \\
\begin{array}{c}\text { Man-hrs/100 } \\
\text { Burrows }\end{array}\end{array}$ & $\begin{array}{c}\text { Cost/100 } \\
\text { Burrows }\end{array}$ & $\begin{array}{l}\text { Reduction } \\
\text { in Activity }\end{array}$ \\
\hline 30 Second & 113 & 51 & $1.77 \mathrm{hrs}$ & $2.50 \mathrm{hrs}$ & $\$ 5.32$ & $-13.0 \%$ \\
\hline 60 Second & 324 & 145 & $1.85 \mathrm{hrs}$ & $6.21 \mathrm{hrs}$ & $\$ 10.64$ & $-63.0 \%$ \\
\hline
\end{tabular}


Table 2. Comparative efficacy, application labor and cost of the "Rodentorch" concussion device and two EPA registered burrow fumigants on ground squirrels.

\begin{tabular}{|c|c|c|c|c|c|c|}
\hline Plot & $\begin{array}{c}\text { Burrows } \\
\text { Closed }\end{array}$ & $\begin{array}{c}\text { Reopened } \\
\text { Burrows } \\
\text { Treated } \\
\end{array}$ & $\begin{array}{c}\begin{array}{c}\text { Pretreatment } \\
\text { Burrow Closure }\end{array} \\
\text { Man-hrs/100 burrows }\end{array}$ & $\begin{array}{c}\frac{\text { Treatment }}{\text { Man-hrs/100 }} \\
\text { Burrows }\end{array}$ & $\begin{array}{c}\text { Cost/100 } \\
\text { Burrows } \\
\end{array}$ & $\begin{array}{l}\text { Reduction } \\
\text { in Activity }\end{array}$ \\
\hline Rodentorch & 454 & 313 & $0.86 \mathrm{hrs}$ & $2.80 \mathrm{hrs}$ & $\$ 7.98$ & $-40.6 \%$ \\
\hline Gas Cartridge & 155 & 102 & $1.08 \mathrm{hrs}$ & $3.10 \mathrm{hrs}$ & $\$ 40.00$ & $-90.8 \%$ \\
\hline $\mathrm{AlPO}_{4}$ & 200 & 186 & $0.66 \mathrm{hrs}$ & $1.61 \mathrm{hrs}$ & $\$ 15.00$ & $-83.7 \%$ \\
\hline
\end{tabular}

and 3.10 man-hours/100 burrows for the gas cartridge application (Table 2).

Cost of application (propane and oxygen) was least expensive for the "Rodentorch" at $\$ 7.98 / 100$ burrows (Table 2). Start-up cost for the purchase of "Rodentorch" application equipment is not taken into account, however. This cost ranges from approximately $\$ 500$ to $\$ 1,000$ dollars depending on the amount of equipment purchased. Cost of the aluminum phosphide application was $\$ 15.00 / 100$ burrows $(\$ 0.075 /$ tablet at 2 tablets/burrow). The gas cartridge cost $\$ 40.00 / 100$ burrows ( $\$ 0.40 /$ gas cartridge at 1 cartridge/burrow).

There appears to be no significant labor savings realized by closure of burrows before treatment. Preclosure of burrows does reduce the cost of treatment (Table 3).

\section{DISCUSSION}

One of the major disadvantages of burrow fumigants or devices such as the "Rodentorch" is that they are labor intensive. When used for ground squirrels or prairie dogs, they are generally practical for application only on small acreages or as a clean up tool following a grain bait rodenticide application. Regardless of their effectiveness, the cost and labor of application greatly limits their use.

The efficacy of gas cartridge and aluminum phosphide burrow fumigants is generally rated as good as illustrated by the results in this study. The efficacy of the "Rodentorch" device, ranging from $13 \%$ to $60 \%$ reduction in activity, can be rated as poor and is not at a level generally recognized as adequate for long term population reduction. If efficacy is used as the primary selection criterion for choosing among the devices tested in these studies, one of the registered burrow fumigants would be the best choice.

The "Rodentorch" device, particularly its concept, is not without merit. It is a reusable device that is easily maintained and serviceable for many years of use. It is relatively inexpensive to operate and propane and oxygen are universally available. The gas mixture, like water from a hose used to drown burrowing rodents, is technically being use as a pesticide but it seems unlikely that EPA would require registration as a pesticide. The use does not have the psychological connotation of a pesticide nor would licensing and certification as a pesticide applicator by the user be required.

The device is potentially hazardous to the user and proper safety instruction and equipment are essential before using this system. The explosions are very loud and good quality hearing protection is necessary. Eye, hand, and arm protection are also needed because of debris that is ejected out of the burrows. Fires may be ignited in dry vegetation. Nontarget burrow occupants may be killed.

The "Rodentorch" device was developed through a trial and error methodology as a technique to control pocket gophers (G. Mertens, pers. comm.). As a result, little information is known about how the gases disburse or behave in the burrow systems, how soil structure and burrow configuration affect the concussive blast, or how the concussive forces affect the target rodents. Knowledge about these and other factors and their application in improving the device or application technique may increase the device's efficacy on ground squirrels and prairie dogs.

G. Mertens (pers comm) stated that the effectiveness of

Table 3. Estimated difference in application time and cost between pretreatment burrow closure regime with only reopened burrows treated and a no preclosure regime where all burrows would be treated. (Ground squirrel plots only.)

\begin{tabular}{llccccc}
\hline & & $\begin{array}{c}\text { Time } \\
(\text { Man-hrs })\end{array}$ & $\begin{array}{c}\text { Burrows } \\
\text { Treated }\end{array}$ & $\begin{array}{c}\text { Time } \\
\text { Difference }\end{array}$ & Cost & $\begin{array}{c}\text { Increased } \\
\text { Cost }\end{array}$ \\
\hline \multirow{2}{*}{ Rodentorch } & Preclosure $^{\mathrm{a}}$ & 12.84 & 313 & & $\$ 28.41$ & \\
Gas Cartridge & No Preclosure $^{\mathrm{b}}$ & 13.01 & 454 & $+1.3 \%$ & $\$ 39.66$ & $+39.6 \%$ \\
& Preclosure $^{\mathrm{a}}$ & 4.83 & 102 & & $\$ 38.80$ & \\
& No Preclosure $^{\mathrm{b}}$ & 4.81 & 155 & $-0.4 \%$ & $\$ 62.00$ & $+59.8 \%$ \\
& Preclosure $^{\mathrm{a}}$ & 4.33 & 186 & & $\$ 27.90$ & \\
$\mathrm{AlPO}_{4}$ & No Preclosure $^{\mathrm{b}}$ & 3.23 & 200 & $-25.4 \%$ & $\$ 30.00$ & $+9.1 \%$ \\
\hline
\end{tabular}

${ }^{a}$ Calculations based on actual data.

${ }^{b}$ Calculations based on the no. of burrows that would have been treated without preclosure of burrows.

Note: If the same percentage of burrows had been reopened on the $\mathrm{AlPO}_{4}$ plot as was reopened on the other plots, the time difference would have been about $-8.2 \%$ and the increase in cost about $+48.1 \%$. 
the device on pocket gophers in Nevada is rated as good, although no controlled evaluations have been conducted. It is also a common practice to apply a gas cartridge to the pocket gopher burrow system after treatment with the device. There is no information on the degree of efficacy each control method contributes to control success. Mertens stated that control appeared better in moist soil than in dry soil indicating that soil composition may be an important factor in the device's efficacy. It was also stated that reports from users indicated that efficacy of the device had been less effective on ground squirrels than pocket gophers. Mertens suggested that the back filling by gophers of their burrow systems confined the concussive effect to a smaller area while the concussive effect may be reduced in open, multiple entrance ground squirrel burrow systems. Reports from users also indicate that the device has been effective on marmot (Marmota spp) and badger (Taxidea taxus).

Increasing the gas injection time to 60 seconds in the prairie dog trials increased percent reduction in activity. This suggests that longer injection times may improve efficacy. However, an injection time that might obtain efficacy of $90 \%$ or greater may require too much time to be operationally feasible except on the smallest of colonies. The quantity of gases needed at which an acceptable efficacy might be achieved may result in unacceptable hazard to the applicator. Cost of application will increase, perhaps comparable to the cost of using registered burrow fumigants.

Modification of the device or application technique is needed to improve efficacy. This may involve some method of injecting the gases deeper in the burrow systems so that the concussive force is more likely to impact the target rodent with lethal effect. Additionally, application time needs to be reduced to make this technique more operationally feasible. Modifications which allow gas injection at a faster rate may be one possibility.

Injection of carbon dioxide $\left(\mathrm{CO}_{2}\right)$ gas into burrow systems using the "Rodentorch" methodology may be an effective control alternative. $\mathrm{CO}_{2}$, which is heavier than oxygen, would sink into the burrow system displacing oxygen and cause death by suffocation. Whether the $\mathrm{CO}_{2}$ would fill the burrow system effectively enough or remain in a pure enough concentration long enough to cause death before being diluted by diffusion of oxygen from the soil structure remains to be tested.

\section{RECOMMENDATIONS}

Data from this study show that the "Rodentorch" is less effective than currently registered rodenticides for controlling black-tailed prairie dogs and Richardson ground squirrels. Also, a significant amount of time is required for application. We would not recommend use of the "Rodentorch" in preference to currently registered rodenticides until evaluation of modifications of the device and/or application technique shows acceptable efficacy of the device for control of prairie dogs and ground squirrels.

Anecdotal information from the manufacturer suggest that efficacy of the "Rodentorch" may be acceptable on pocket gophers. We recommend further evaluation of the device to make this determination. Evaluation should be made using the device alone and with follow up application of a burrow fumigant. Comparative trials with currently recommended pocket gopher control techniques to compare efficacy, cost and labor of application should also be conducted.

\section{ACKNOWLEDGMENTS}

We wish to thank Wayne Hannah, Montana distributor of "Rodentorch," for providing and operating the "Rodentorch" device used in these studies. Larry Handegard and Phil Johnson assisted with the applications. Dave Able and Maurice Hunsaker allowed the use of their properties for these studies.

\section{LITERATURE CITED}

MERTENS, G., Personal Communications, Mertens' Repair Shop ("Rodentorch" manufacturer), 127 Rt 95 North, Orovada, Nevada 89425. 